\title{
Functional Characterization of Embryonic Stem Cell-Derived Endothelial Cells
}

\author{
Drew E. Glaser ${ }^{a}$ Robert M. Gower ${ }^{d}$ Nicholas E. Lauer ${ }^{a} \quad K^{2}$ ayan Tam ${ }^{d}$ \\ Alicia A. Blancas ${ }^{b}$ Albert J. Shih ${ }^{c}$ Scott I. Simon ${ }^{d}$ Kara E. McCloskey ${ }^{a-c}$ \\ ${ }^{a}$ Graduate Program in Biological Engineering and Small-Scale Technologies, ${ }^{b}$ Graduate Program in \\ Quantitative and Systems Biology, and 'School of Engineering, University of California, Merced, Calif., and \\ ${ }^{\mathrm{d}}$ Department of Biomedical Engineering, University of California, Davis, Calif., USA
}

\section{Key Words}

Embryonic stem cell $\cdot$ Endothelial cell $\cdot$ Endothelial progenitor cell $\cdot$ Vascular progenitor cell $\cdot$ Endothelium • Extracellular matrix $\cdot$ Nitric oxide $\cdot$ Shear stress $\cdot$ Ephrin . Arterial $\cdot$ Venous $\cdot$ Inflammation

\begin{abstract}
Endothelial cells (EC) derived from embryonic stem cells (ESC) require additional functional characterization before they are used as a cell therapy in order to enhance their potential for engraftment and proliferation. We explore several physiologically relevant functions of ESC-derived EC (ESC$\mathrm{EC})$, such as its capacity to produce nitric oxide (NO), regulate permeability, activate and express surface molecules for the recruitment of leukocytes in response to inflammatory stimuli, migrate and grow new blood vessels, lay down extracellular matrix, and take up low-density lipoproteins. We also examined the ESC-EC ability to upregulate NO in response to shear stress and downregulate $\mathrm{NO}$ in response to pro-inflammatory TNF- $\alpha$ activation. Functional responses of ESCEC were compared with those of cultured mouse aortic ECs. The ESC-EC exhibit most aspects of functional endothelium, but interesting differences remain. The ESC-EC produced less $\mathrm{NO}$ on a per cell basis, but the same amount of NO if quantified based on the area of endothelial tissue. They also
\end{abstract}

exhibit increased angiogenic sprouting and are more resistant to inflammatory signals. We further characterized the subphenotype of our ESC-EC and observed both venous and arterial markers on individual cells with a larger percentage of the cells exhibiting a venous phenotype. These data support the hypothesis that the developmental default pathway is toward a venous EC, and that refinement of methods for differentiation towards arterial EC is required to maintain a homogeneous population.

Copyright $\odot 2011$ S. Karger AG, Basel

\section{Introduction}

Vascular progenitor cells derived from stem cells are a promising source of endothelium for a diverse set of applications including seeding of arterial stents and tissue engineering for repair of ischemic and diseased tissues [1]. One major obstacle associated with using embryonic stem cells (ESC) for regenerative medicine applications is the isolation and culture of homogeneous populations of differentiated cells that are functional while also retaining the potential for expansion and incorporation into matrices and tissues. Our laboratory has developed methods for the differentiation and isolation of homogeneous endothelial cells (EC) from mouse ESC. We have also

\section{KARGER}

๑) 2011 S. Karger AG, Basel

Fax +41 613061234 E-Mail karger@karger.ch www.karger.com www.karger.com/jvr
Dr. Kara E. McCloskey

School of Engineering

University of California, Merced

P.O. Box 2039, Merced, CA 95344 (USA)

Tel. +1 209228 7885, E-Mail kmccloskey@ucmerced.edu 
characterized these cells for a variety of endothelial specific markers using immunofluorescent labeling [2-5]. Lineage-specific markers that correlate with histological and phenotypic characteristics of somatic cells is routinely applied for the classification of many types of differentiated stem cells. Common EC markers include endothelial nitric oxide synthase (eNOS), receptors for vascular endothelial growth factors (VEGF) Flk-1 and Flt-1, vascular endothelial cadherin (VE-cadherin), CD34 and platelet EC adhesion molecule (PECAM-1). As previously published, our ESC-derived EC (ESC-EC) express these markers indicating their lineage-specific commitment, and do not contain cells expressing nondifferentiated ESC or smooth muscle cells [3, 4].

In addition to surface marker characterization, functional assays are also essential determinants of appropriate cellular maturation. Since EC or endothelial progenitor cells (EPC) differentiated in culture from stem cells are exposed to a more limited repertoire of the differentiation cues that are experienced in vivo, it is especially important to assess functional capability in addition to marker analysis. For the EC, physiologically relevant functional assays include the ability to synthesize nitric oxide (NO), regulate permeability (that is, the flux of molecules across an intact endothelium), respond to inflammatory activation by tumor necrosis factor- $\alpha$ (TNF$\alpha$ ), migrate and grow new blood vessels, and produce appropriate extracellular matrix (ECM) for developing a basal lamina. Characterization of in vitro-derived ESC$\mathrm{EC}$ and their response to environmental cues and inflammation is a critical step in assessing the quality of cultured cells for clinical application in cell-based therapies.

\section{EC Synthesize and Release NO}

EC regulate blood pressure and blood flow by releasing the vasodilators including: $\mathrm{NO}$ and prostacyclin, as well as vasoconstrictors including: endothelin and platelet-activating factor. Production of these molecules is critical for maintaining vascular homeostatic function [6]. Release of $\mathrm{NO}$ by the EC relaxes the smooth muscle cells in the walls of the arterioles, and is the principal factor that regulates dilation of the vessel wall and, in turn, blood flow. NO also inhibits the aggregation of platelets and thus keeps inappropriate clotting from interfering with blood flow. NO is synthesized within EC (among other cells) by eNOS. eNOS and NO secretion is constitutively active in EC, but is also upregulated by certain stimuli, such as laminar shear stress [7-10]. The mechanisms underlying the shear stress-induced eNOS expression include enhancing eNOS gene transcription and stabilizing eNOS mRNA. In both of the cases, the tyrosine kinase c-Src played a central role, and a complex kinase cascade including Raf, Ras, MEK1/2 and ERK1/2 seems to be involved in the signal transduction leading to eNOS transcription by shear stress [11]. In addition, TNF- $\alpha$ stimulation has been shown to downregulate eNOS mRNA, protein and activity in EC via destabilization of eNOS mRNA [12].

\section{EC Regulate Vascular Permeability to Macromolecules and Protein}

In addition to regulating blood flow, endothelium plays a vital role in regulating the transport of fluids, molecules and cells between the bloodstream and surrounding tissue. An EC monolayer is relatively impermeable, $<1 \%$ flux, to large molecules $(1-100 \mathrm{kDa})$. The presence of membrane-bound receptors helps facilitate this gatekeeping role for numerous molecules including proteins, lipid-transporting particles, metabolites and hormones [6]. A number of investigators have successfully grown EC on porous supports to create in vitro models of permeability [13-15] for studying the permeability of the EC monolayer under various conditions. Transient increases in endothelial permeability do occur normally after tissue injury; however, chronic increases in permeability is abnormal and has been implicated in atherosclerosis, diabetic retinopathy and tumor growth [16].

\section{EC Are Building Blocks for Generating New Blood \\ Vessels}

It is widely accepted that the new blood vessels arise through two mechanisms during development, called vasculogenesis and angiogenesis [17]. Vasculogenesis is a process in which hemangioblasts, EC precursors from mesodermal origins, grow and organize to form vascular networks. Angiogenesis is the formation of new blood vessels by sprouting from existing vessels. Recently, an alternative view has demonstrated the presence of circulating EC in the adult [18] and their incorporation into ischemic tissue [19], suggesting a role for vasculogenesis in the adult as well as in the embryo. It is now thought that both angiogenesis and vasculogenesis occur during postnatal life and that they are not mutually exclusive events. Both angiogenesis and vasculogenesis require EC proliferation, migration and three-dimensional organization [20]. The ability of EC to form lines and tube-like formations in vitro has been demonstrated to be a good measure of vasculogenic and angiogenic potential in tissue. A variety of culture conditions for generating these vascular structures have been employed, including culturing cells on the surface of collagen or fibrin gels, on a 
thin layer of fibronectin, using a Matrigel invasion assay, collagen or fibrin gel sandwich assay, or by directly embedding EC in three-dimensional gels [for review, see 2]. One of the most common (and controversial) assays involves seeding EC directly on Matrigel. Although a common assay for EC function, recent evidence suggests that the EC may also be responding to tension forces of cellular traction due to the low rigidity of the adhesive support [21-23], rather than undergoing true vasculogenesis. Angiogenesis, on the other hand, can be observed using the simple Matrigel assay and observing evidence of new cell proliferation and sprout formations.

\section{EC Produce ECM}

Vascular endothelium is tightly associated with a basal lamina that consists of multiple ECM molecules arranged in a sheet-like structure that supports the endothelium [24]. The ECM of EC is also vital to cell signaling processes and structural developments [25] in order to stabilize their microenvironment and to provide a niche for the vascular tissue. EC lining the lumen of blood vessels produce their own ECM material components during the formation of a basement membrane, which separates endothelial layer from the underlying smooth muscle cells. This basement membrane is composed of a variety of ECM materials including collagen type IV, laminin and fibronectin. Collagen type IV is a network-forming collagen that is the most abundant factor in the ECM-surrounding blood vessels providing structural stability [26]. Laminin is another major component of the basement membrane around blood vessels. Laminin- 8 and laminin-10 are specific isoforms produced by EC [27]. Laminin interacts with collagen type IV in the basement membrane and helps stimulate growth and differentiation of vascular cells [28]. Laminin is also specifically necessary for maturation of vascular smooth muscle cells in the blood vessel [38]. Previous studies have shown laminin to be more actively produced in subconfluent EC cultures, with a decrease in laminin production once cells become more densely packed [29]. Fibronectin is another insoluble protein component of the ECM and is found as a soluble disulfide-linked dimer in the plasma. Recent studies suggest that fibronectin is a key component of vasculogenesis [30,31], and that unlike laminin, fibronectin production by EC is independent of cell density [29].

\section{Inflammation and EC Activation}

During inflammation the endothelium alters its adhesive properties supporting leukocyte recruitment by sequential binding of selectins, chemokines and $\beta_{2}$-inte- grins that function cooperatively to elicit rolling, arrest and transmigration. In vitro, endothelium can be 'activated' using acute inflammatory cytokines such as TNF$\alpha$. This, in turn, activates a mitogen-activated protein kinase signaling pathway that leads to the transcription and upregulation of cell adhesion molecules including E-selectin, ICAM-1 and VCAM-1 as well as chemokines which guide recruitment of leukocytes $[32,33]$. The process also facilitates the homing of highly proliferative endothelial progenitor cells and thus is important in both neovascularization in regions of ischemia or re-endothelialization of areas where the endothelium is denuded $[34,35]$.

\section{Low-Density Lipoprotein Uptake}

Normal EC are able to take up low-density lipoprotein (LDL), a lipoprotein that carries cholesterol through the bloodstream, and these functions transport cholesterol to the arteries. Not only is LDL uptake an important EC function, it is one of the most commonly used assessments for identification of an EC. Studies have shown that in areas of low and disturbed flows, normally active atheroprotective genes are suppressed and the pro-atherogenic genes are upregulated, leading to an increase in the engagement and synthesis of LDL cholesterol by EC and an increase in the permeability of the endothelium to LDL. This ultimately promotes the subendothelial accumulation of LDL [36]. Oxidative stress is also increased by promoting the production of reactive oxygen species and oxidation of LDL [36].

\section{Vascular Diversification at the Cellular Level}

The vascular system is a complex network of arteries that transport oxygen-rich blood to tissues and veins that carry the oxygen-depleted blood back to the heart. Arterial endothelia are surrounded by a thick layer of smooth muscle cells embedded in collagen, whereas venous endothelia lack smooth muscle cells. Due to these anatomical and physiological differences, one expects that the endothelium for these structures would have distinct molecular signatures. Recent discoveries of molecular markers for arterial, venous and lymphatic EC now allow a more sophisticated characterization of endothelial diversity $[37,38]$. Arterial specification, promoted by Notch signaling, is characterized by ephrinB2, delta-like (Dll)-4, Notch1 and 4, Jagged-1, and connexin-40 expression. Venous endothelium, potentially a default pathway of EC differentiation [39], is characterized by EphB4 and COUP-TFII. Committed lymphatic EC, differentiated from venous EC, express Prox-1 as the most specific lymphatic EC marker. 
For the EC that might be used clinically for cell therapies, especially if derived in vitro from stem cells, it is important that these cells function similar to those in vivo counterparts. Here, we examined the capacity of in vitro stem cell-derived EC to produce $\mathrm{NO}$, regulate permeability, activate and express surface molecules for the recruitment of leukocytes in response to inflammatory cues, migrate and grow new blood vessels, lay down appropriate ECM for the basal lamina, and to take up LDL. We then compared the responses of ESC-EC within cultured mouse aortic ECs (MAEC). These assays reflect some of the most important known functions of a mature EC.

\section{Methods}

\section{ESC Cell Culture}

Mouse D3-ESC (American Type Culture Collection) were initially maintained on irradiated or mitomycin C-treated (Sigma) mouse embryonic fibroblast feeder layers in knockout Dulbecco's modified Eagle medium (KO-DMEM; Gibco) containing 15\% ES cell-qualified FBS (Gibco), 5\% knockout serum replacement (Gibco), 1,000 units/ml of leukemia inhibitory factor (ESGRO; Chemicon International) and $5 \times 10^{-5} \mathrm{M} \beta$-mercaptoethanol. Cells were then cultured on $0.1 \%$ gelatin (no feeders) for 1 week before switching to differentiation conditions.

\section{EC Derivation from ESC}

The EC used in these studies are derived from mouse ESC using previously published protocols [3-5]. Briefly, initial induction of EC required 4 days of culture on collagen type IV-coated dishes in media containing FBS and without leukemia inhibitory factor. Differentiation medium consisted of $93 \% \alpha$-minimal essential medium, 5\% FBS, $1 \%$ penicillin/streptomycin, $1 \%$ L-glutamine and $5 \times 10^{-5} \mathrm{M} \beta$-mercaptoethanol. The cells expressing Flk-1 were then sorted using fluorescence-activated cell sorting (FACS) and allowed to grow for 1 week on collagen type IV-coated dishes. After 1 week, the Flk-1-positive cells exhibited 2 phenotypes: elongated smooth muscle morphology or cobblestone-like endothelial morphology. The cells that had more endothelial morphology were manually or magnetically (MACS; Miltenyi Biotec) selected and fed EC medium (EGM-2 supplemented with EGM-2 Bullet Kit from Clonetics; $10 \mathrm{ml} \mathrm{FBS,} 0.2 \mathrm{ml}$ hydrocortisone, $2 \mathrm{ml} \mathrm{hFGF-} \beta, 0.5 \mathrm{ml}$ VEGF, $0.5 \mathrm{ml}$ R3-IGF- $1,0.5 \mathrm{ml}$ ascorbic acid, $0.5 \mathrm{ml}$ hEGF, $0.5 \mathrm{ml} \mathrm{GA}-1000,0.5 \mathrm{ml}$ heparin plus $5 \times$ $10^{-5} \mathrm{M} \beta$-mercaptoethanol and an extra $50 \mathrm{ng} / \mathrm{ml}$ of recombinant human VEGF, VEGF 165 , from R\&D Systems). Methods consistently yielded 25 population doublings at $>95 \%$ purity.

\section{Isolation of Mouse Aortic ECs (MAEC)}

Adult $129 / \mathrm{Sv}+\mathrm{c} / \mathrm{p}$ mice (Jackson Laboratories) were anaesthetized using isoflurane before cervical dislocation. The abdominal aorta was removed, cleaned, cut into small pieces, and placed on Matrigel drops with $0.1-0.2 \mathrm{ml}$ of EC medium (above). EC were allowed to migrate out of the aortas for 7 days before aortas were removed to prevent smooth muscle cell migration. EC outgrowths were purified using a combination of manual selection based on morphology, and magnetic selection (MACS; Miltenyi Biotec).

\section{NO Production}

NO, normally produced by EC, is a free radical that is responsible for vasodilatation of blood vessels. Because of its unstable nature, $\mathrm{NO}$ quickly degrades into nitrate $\left(\mathrm{NO}_{3}^{-}\right)$and nitrite $\left(\mathrm{NO}_{2}{ }^{-}\right)$, but relative proportions of $\mathrm{NO}_{2}{ }^{-}$and $\mathrm{NO}_{3}{ }^{-}$within a sample are variable and cannot be predicted with certainty; therefore, the best index for measuring total NO production is the sum of both these products. The original amount of $\mathrm{NO}$ produced by the EC is calculated from measurements of $\mathrm{NO}_{3}{ }^{-}$and $\mathrm{NO}_{2}{ }^{-}$in the culture medium using a nitrate/nitrite fluorometric assay kit (Cayman Chemicals). A nitrate standard curve was first performed in order to quantify sample nitrate and nitrite concentrations for a range of absorbance measurements. Confluent monolayers of EC were cultured on gelatin-coated $100-\mathrm{mm}$ dishes in $7 \mathrm{ml}$ of media without ascorbic acid. After 3 days, the media were collected and stored at $-20^{\circ} \mathrm{C}$ for $\mathrm{NO}$ quantification. The amount of NO produced by the cells was quantified and then subtracted from the basal amounts of NO in the medium without cells. The cells in each dish were also counted and used to normalize the amount of NO production per cell. We also examined the NO production after treating cells with 0.1 and $10 \mathrm{ng} / \mathrm{ml}$ of pro-inflammatory TNF- $\alpha$ and after exposing cells to shear stress for 3 days.

\section{Shear Stress}

A cone-and-plate shear apparatus was used to exposed ESCEC and MAEC to shear stress [40,41]. The Teflon cone has a fixed 0.5 -degree angle and is rotated at a constant speed to create defined levels of shear stress. The entire shear system is housed in a humidified tissue culture incubator $\left(5 \% \mathrm{CO}_{2}, 37^{\circ} \mathrm{C}\right)$. The shear stress level $\left(\mathrm{T}_{\omega}\right)$ experienced by the cells is controlled by viscosity $(\mu)$ and angular velocity $(\omega)$, and is inversely proportional to cone angle $(\alpha)$. The shear system is designed to be used with $100-\mathrm{mm}$ tissue culture dishes (Falcon) and the Teflon lids are designed to allow free gas exchange between the cells and in the incubator environment while preventing contaminations. ESC-EC and MAEC were exposed to 20 dynes $/ \mathrm{cm}^{2}$ and for 3 days. The medium was then collected and analyzed for NO content.

$$
T_{\omega}=\frac{\mu \omega}{\alpha}
$$

\section{Permeability}

MAEC and ESC-EC were cultured in normal conditions on gelatin with EC medium (above) and then seeded at 50,000 cells/ well onto $0.4-\mu \mathrm{m}$ pore-size gelatin-coated transparent cell culture inserts (Falcon) fitted in wells of a 12 -well dish (Falcon). Control wells without cells were also used to normalize the $100 \%$ flux. Once cells were confluent, the inserts were washed and moved to a new 12-well dish. Two sizes of molecule were used to determine the permeability of the cells, sodium fluorescein (Pfaltz and Bauer; S05367, MW: $376 \mathrm{Da}$, excitation of $440 \mathrm{~nm}$ and an emission of $525 \mathrm{~nm}$ ) and fluorescein-labeled dextran (Invitrogen; D-1823, MW: 70,000 Da, excitation of $494 \mathrm{~nm}$ and an emission of $518 \mathrm{~nm}$ ). Both molecules were diluted in HEPES $1 \mathrm{M}$ buffer (Fisher). The final concentrations of sodium fluorescein and fluorescein-labeled dextran were 10 and $165 \mu \mathrm{g} / \mathrm{ml}$, respectively, and were add- 
ed to the upper compartment of the EC-coated inserts and allowed to incubate for $20 \mathrm{~min}$ at $37^{\circ} \mathrm{C}$ and $5 \% \mathrm{CO}_{2}$. The solutions in the lower compartments below the inserts were analyzed using SpectraMax M2 (Molecular Devices).

\section{Vasculogenesis/Angiogenesis}

Matrigel (BD Biosciences) was added to a few wells of a 24-well plate in $500-\mu \mathrm{l}$ volumes and allowed to solidify for $30 \mathrm{~min}$ at $37^{\circ} \mathrm{C}$. After the Matrigel solidified, 40,000 ESC-derived EC and MAEC were suspended in $1 \mathrm{ml}$ of EC medium and added to individual Matrigel-coated wells. The cells were then incubated at $37^{\circ} \mathrm{C}$ and $5 \% \mathrm{CO}_{2}$, and observed for tube-like formations with a phase contrast microscope. Vessel structures were examined for apoptosis (programmed cell death) using a TUNEL assay (in situ cell death detection kit, peroxidase; Roche) following the manufacturer's instructions. Quantitative analysis of sprout number and length was accomplished using ImageJ. Images were opened in ImageJ, inverted, converted into 8-bit images and saved in *.tiff format. These images were then used for analysis in NeuronJ. The vessels and sprouts were traced manually, and the length of each was quantified using the 'measure tracings' function.

\section{Extracellular Matrix}

MAEC and ESC-EC were seeded at 80,000 cells per $35-\mathrm{mm}^{2}$ dish and grown to confluence for 1 week. After 3 additional days of culture, cells were fixed with $4 \%$ formaldehyde solution and individual dishes were stained for the following ECM proteins: collagen I, collagen IV, laminin and fibronectin (AbCam). Primary rabbit antibody concentrations of $1 \mu \mathrm{l}$ in $200 \mu \mathrm{l}$ PBS were added to individual dishes and allowed to incubate with antibody overnight. Pre-absorbed anti-rabbit FITC secondary antibodies (Fitzgerald) were added to the collagen I and fibronectin dishes, pre-absorbed anti-rabbit TRITC secondary antibodies (Fitzgerald) were added to the collagen IV and laminin dishes, and dishes were incubated for $1 \mathrm{~h}$ in the dark. 4',6-diamidino-2-phenylindole at $30 \mathrm{nM}$ concentration was also added to during the second incubation stage for $1 \mathrm{~h}$. Images were taken using a Lecia fluorescent microscope.

Inflammation: TNF- $\alpha$ Induced Adhesion Molecule Expression MAEC and ESC-EC were seeded in 6-well plates (BD Falcon) coated with rat-tail collagen 1 (BD Biosciences) at a density of $4,000 / \mathrm{cm}^{2}$ and grown to confluence using EGM-2 media (Lonza). Confluent monolayers were incubated with 0.1 or $10 \mathrm{ng} / \mathrm{ml}$ recombinant mouse TNF- $\alpha$ (R\&D Systems) for $4 \mathrm{~h}$. Cells were removed from adherent culture with disassociation buffer (Invitrogen), put on ice, and labeled with anti-ICAM-1 FITC (Biolegend) or anti-VCAM-1 FITC (Biolegend). Vendor-matched isotype controls were also employed. Data was acquired on a BD FACScan cytometer (BD Biosciences).

\section{LDL Uptake}

ESC-EC and MAEC were seeded onto MatTek glass-bottomed $35-\mathrm{mm}$ plates coated with rat-tail collagen 1 (BD Biosciences) at 40,000 and 20,000 cells $/ \mathrm{cm}^{2}$, respectively. Once confluent, cells were incubated with Alexa Fluor 488 acetylated-LDL (Invitrogen) diluted 1:100 in DMEM with high glucose (Invitrogen) for $4 \mathrm{~h}$ at $37^{\circ} \mathrm{C}$ in order to measure LDL uptake. The slides were then stained with DRAQ5 (Biostatus Limited) according to the manufacturer's instructions and fixed with $4 \%$ paraformaldehyde.
Cells were imaged using a Nikon fluorescence microscope (TE 2000).

\section{EC Subphenotype Characterization}

ESC-EC and MAEC were plated at 40,000 and 20,000 cells/ $\mathrm{cm}^{2}$, respectively, and grown to confluence on gelatin-coated plates, for approximately 3 days. The disparity in cell-plating densities arises due to the fact that ESC-EC are smaller and plate in more densely packed cobblestone-shaped arrangements [4]. Upon reaching confluence, cells were isolated using cell dissociation buffer (Gibco), fixed with $4 \%$ formaldehyde and permeablized with $0.7 \%$ Triton X-100 for $10 \mathrm{~min}$. Cells were stained with primary anti-EphB4 goat polyclonal IgG (Santa Cruz) followed by staining with secondary donkey anti-goat FITC (Fitzgerald), anti-Notch-1 mouse FITC (Abcam), anti-delta-4L Armenian hamster PE (BioLegend) and anti-Prox-1 rabbit (Abcam) antibody followed by anti-rabbit PE (Abcam) including all matching isotype controls. Samples were then analyzed using a BD Bioscience LSRII.

Statistical Analysis

For statistical significance, data were acquired and pooled for each treatment group and treatment groups were repeated 3 times each. Statistical significance was measure using a pairwise t test.

\section{Results}

\section{ESC-EC Synthesize and Release NO}

NO produced by the ESC-derived EC and MAEC was calculated by measuring the total amount of NO products released into the media (fig. 1a). The total amount of $\mathrm{NO}$ produced per surface area did not differ significantly between MAEC and ESC-EC (fig. 1a). However, since the MAEC are larger cells $\left(\mathrm{D}_{\mathrm{avg}}=17.1 \mu \mathrm{m}\right)$ with a correspondingly lower packing density compared with the smaller ESC-EC $\left(\mathrm{D}_{\mathrm{avg}}=15.8 \mu \mathrm{m}\right)$ [4], the data were normalized to the amount of NO produced per cell (fig. 1b), showing that the ESC-derived EC produced significantly lower amounts of $\mathrm{NO}$ than the NO produced by the MAEC on a per cell basis (fig. 1b). We also examined the amount of NO produced after inflammatory stimulation with low and high doses of TNF- $\alpha$ and after exposure to shear stress. As expected [12], both the MAEC and ESCEC showed a trend towards reduced total NO production per surface area after high-dose TNF- $\alpha$ treatment (10 ng/ $\mathrm{ml}$ ) for 3 days, but neither reductions was statistically significant (fig. 1a). However, the reduction in NO production on a per cell basis after high-dose TNF- $\alpha(10 \mathrm{ng} / \mathrm{ml})$ was significant for ESC-EC (fig. 1b), but not the MAEC. We also examined the NO production modulated by fluid shear stress. We detected a marked increase in NO production per cell for both MAEC and ESC-EC after exposure to 20 dynes $/ \mathrm{cm}^{2}$ of shear stress for 3 days, as expect- 


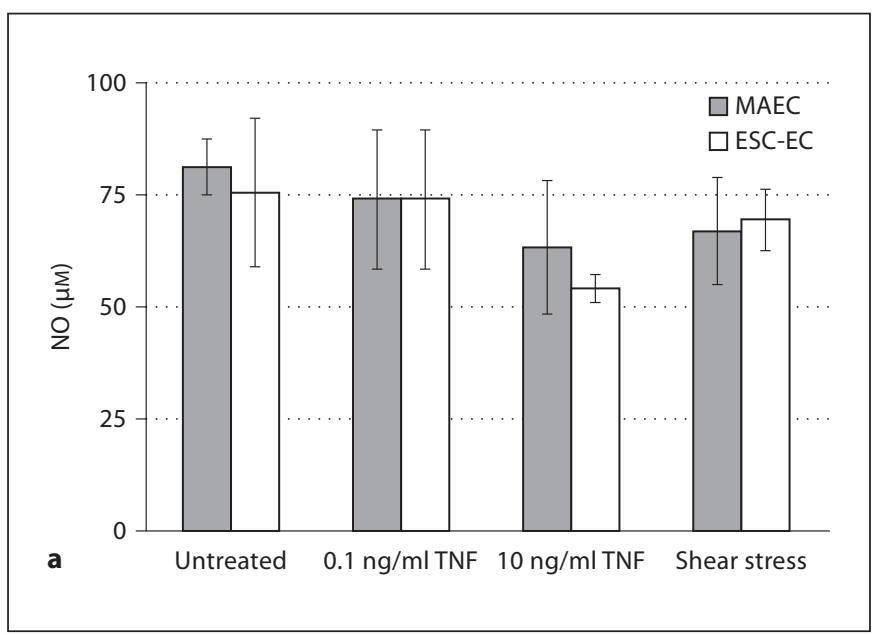

Fig. 1. ESC-EC synthesize NO. a The NO production of ESC-EC and MAEC was measured for untreated cells, after 0.1 and $10 \mathrm{ng} /$ $\mathrm{ml}$ of TNF- $\alpha$ treatment, and after exposure to shear stress for 3 days. The NO production of ESC-EC and MAEC was similar if considered as a cell monolayer in a $100-\mathrm{mm}^{2}$ dish (per surface area) as would be seen in vivo. b However, because the ESC-EC are smaller in size and exhibit tighter packing densities, the data

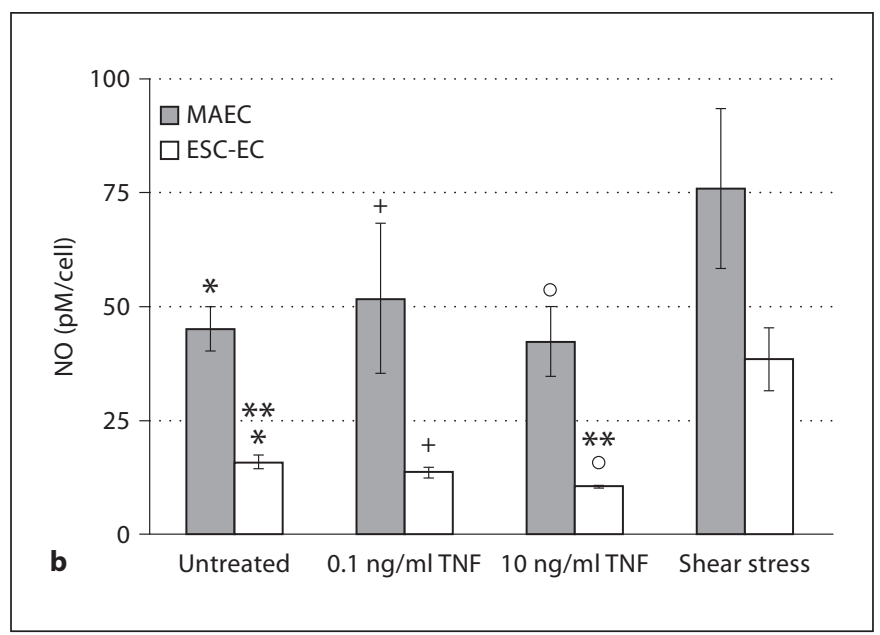

were additionally normalized to the amount of NO produced per cell. On a per cell basis, the NO production by MAEC was significantly greater than ESC-EC $\left({ }^{*} \mathrm{p}<0.05,{ }^{+} \mathrm{p}<0.05,{ }^{\circ} \mathrm{p}<0.05\right)$ and the NO production significantly decreased after $10 \mathrm{ng} / \mathrm{ml}$ of TNF- $\alpha$ stimulation $\left({ }^{* *} \mathrm{p}<0.05\right)$. Additionally, the NO production per cell increased after shear stress treatment in both cell populations, but neither was statistically significant.
Fig. 2. ESC-EC inhibit flux of molecules through endothelium. The permeability of ESC-EC and MAEC was indirectly measured by quantification of the percent of molecules allowed to cross the endothelium. The ESC-EC and MAEC did allow 57$67 \%$ of small sodium fluorescein molecules to cross the endothelium, while inhibiting the larger dextran molecules. In addition, the difference in the flux of molecules through the ESC-EC and MAEC was not statistically significant $(\mathrm{p}<0.05)$.

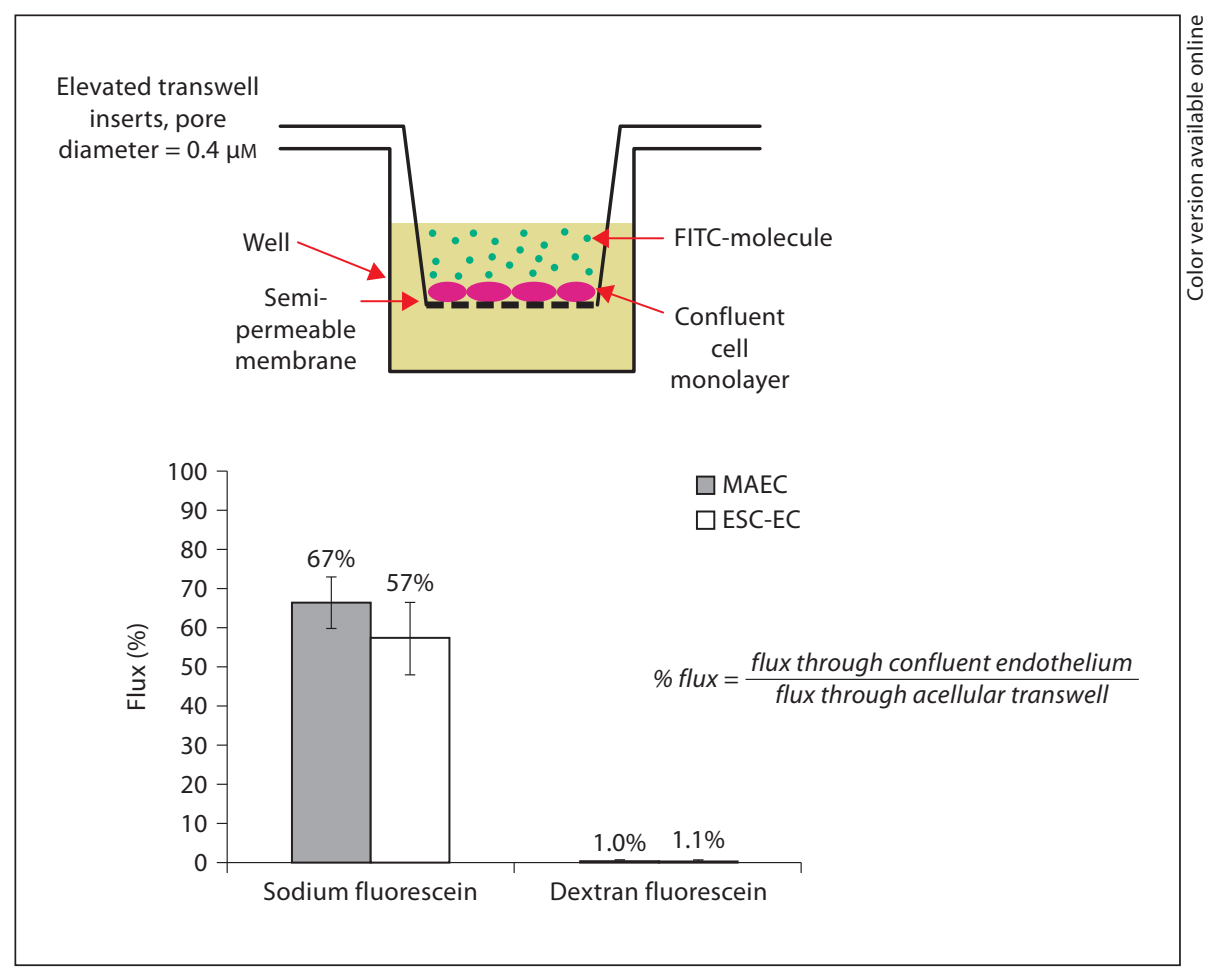




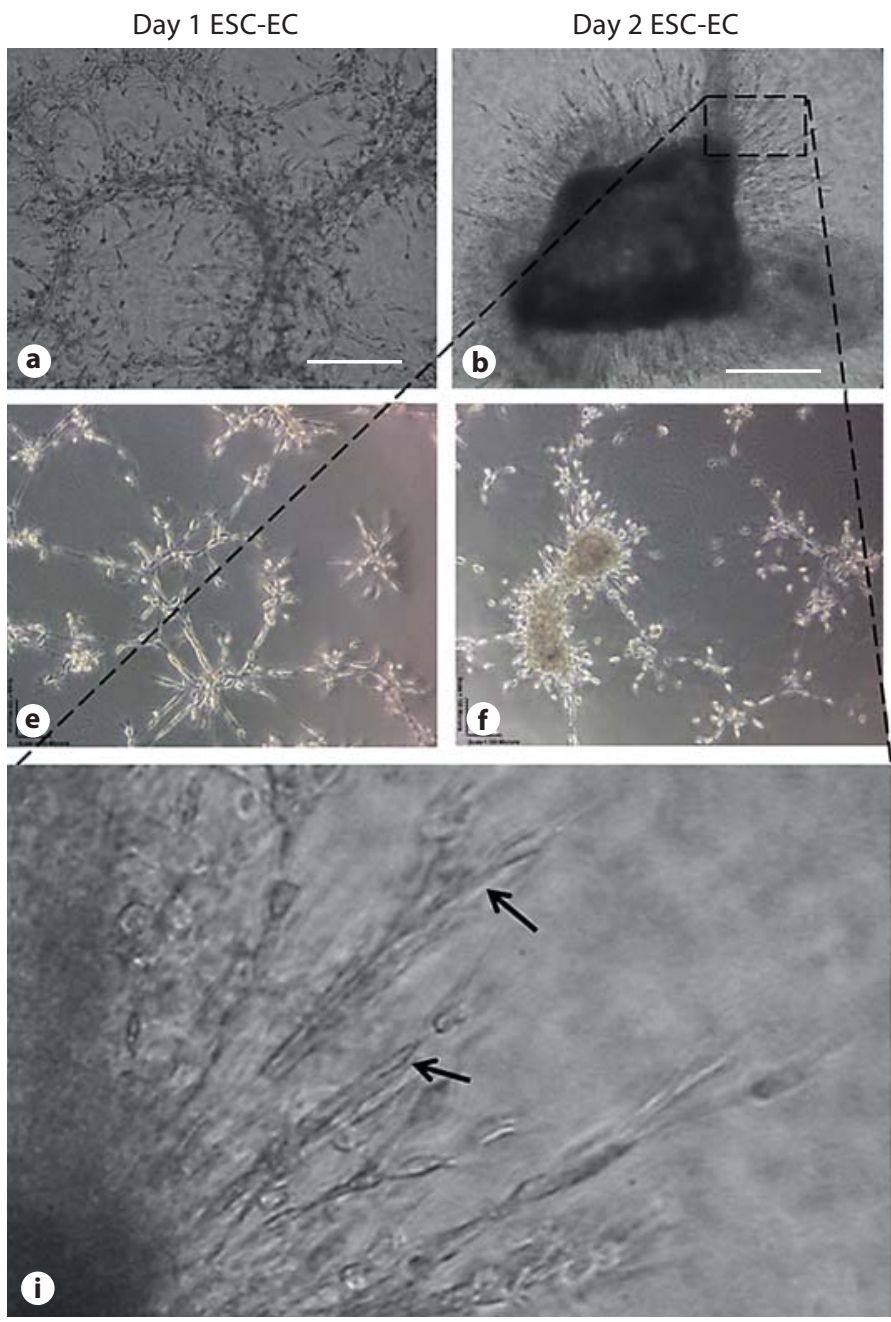

Fig. 3. ESC-EC generate vascular networks on Matrigel. The ESCEC migrated into cord-like structures after 1 day on Matrigel (a), but also continued to migrate, proliferate, and sometimes assembled into central mass-like structures with additional sprouting by day 2 (b). In comparison, the MAEC migrated and formed cord-like structures after 1 day on Matrigel (c), but then began to show increased signs of regression by day 2 (d). e-h The networks were analyzed for evidence of apoptosis using a TUNEL assay. Apoptosis (brown in the online version) was observed after 2 days
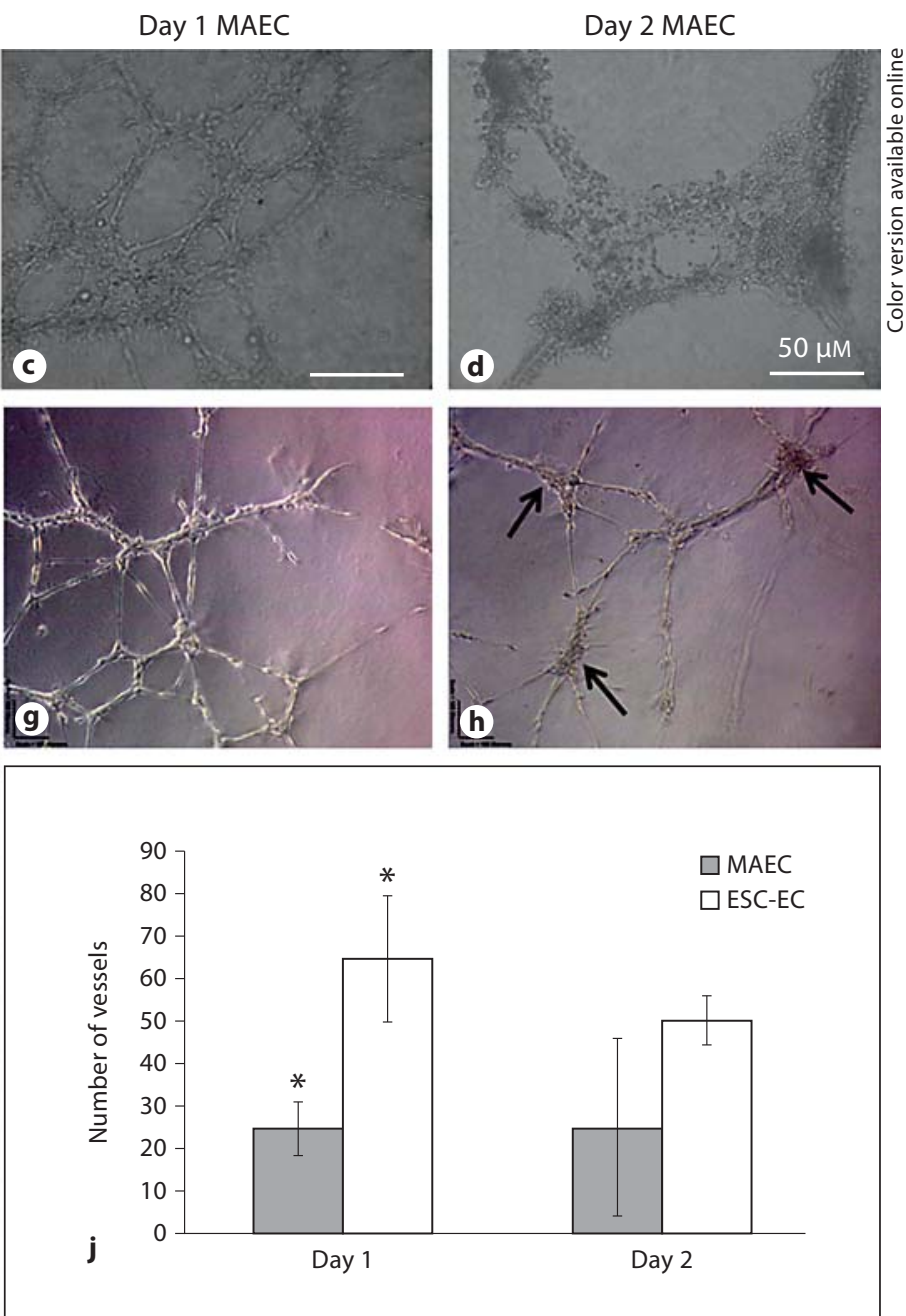

in the MAEC and the central mass-like structures of the ESC-EC. i At higher magnification, we see elongated continuous sprouting by the ESC-EC cells on day 2. j Quantification of the vascular networks indicates increased total vessel numbers in the ESC-EC compared with MAEC, significant at day $1\left({ }^{*} \mathrm{p}<0.10\right)$. However, looking at the average lengths of these vessels, the ESC-EC exhibited shorter (mean length $=130 \mu \mathrm{m})$ sprout-like structures compared with the longer vessels (mean length $=300 \mu \mathrm{m}$ ) generated by the MAEC. ed [7-10], but this increase was also not statistically significant. The combined data in figure $1 \mathrm{a}$ and $\mathrm{b}$ indicate that both EC populations modulate $\mathrm{NO}$ to defined pro(TNF- $\alpha$ ) and anti-inflammatory (shear) stimulation, although not necessarily at levels considered to be statistically significant. Additionally, interesting differences remain between the NO produced by a confluent monolayer of EC and those normalized on a per cell basis. No- tably, the NO produced by the ESC-EC on a per cell basis was significantly lower than the NO produced by the MAEC on a per cell basis (fig. 1b), but the NO produced per area by ESC-EC monolayers (as would be seen if using these cells to coat the vascular wall in vivo) made up of smaller cells is equivalent to the MAEC. 

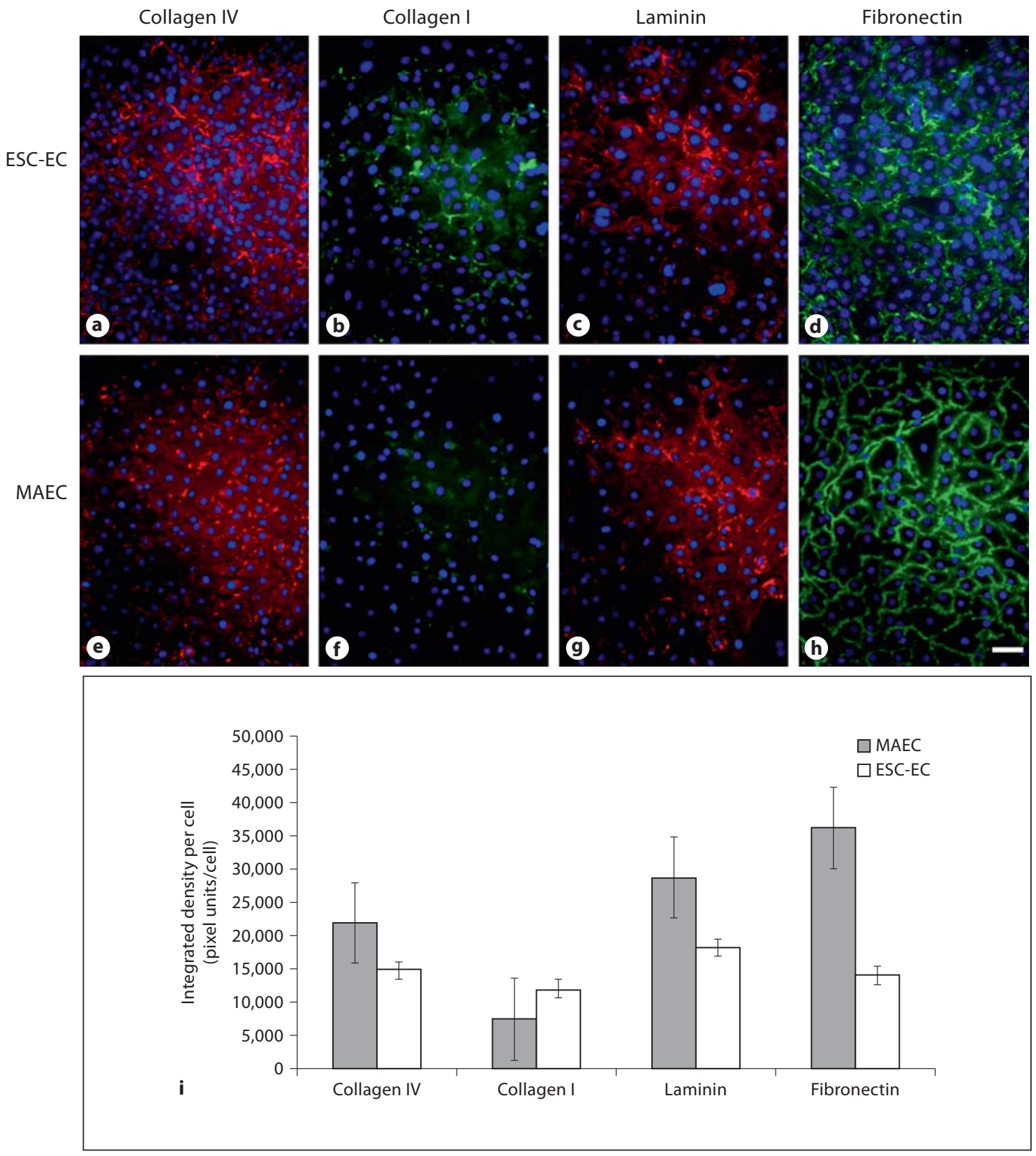

Fig. 4. ESC-EC synthesize ECM materials. a-d The ESC-EC did produce ECM materials collagen type IV, laminin and fibronectin, and to a lesser extent, collagen type I. e-h The MAEC also synthesized all materials except collagen type I. i The quantitative analysis of the ECM material synthesized per cell indicate greater laminin and fibronectin production by MAEC compared with ESC-EC. Scale bar = $25 \mu \mathrm{m}$.

\section{ESC-EC Form an Endothelium for Regulation of \\ Permeability}

We next determined the permeability of MAEC and ESC-EC based on the flux of small- and large-size molecules: sodium fluorescein $(376 \mathrm{Da})$ and fluorescein dextran $(70,000 \mathrm{Da})$ across a monolayer of EC cultured to confluence on an elevated porous insert. The flux relative to the acellular collagen I-coated transwell filter for sodium fluorescein was $67 \%$ for the MAEC and $57 \%$ for the ESC-EC, as compared to $1 \%$ for the larger fluoresceinlabeled dextran, confirming that both MAEC and ESCEC were confluent and able to prevent the flux of protein- 
Fig. 5. ESC-EC (a, b) and MAEC (c, d) take up LDL. Green shows LDL uptake, blue shows DRAQ5 nuclear stain. Scale bar = $50 \mu \mathrm{m}$.
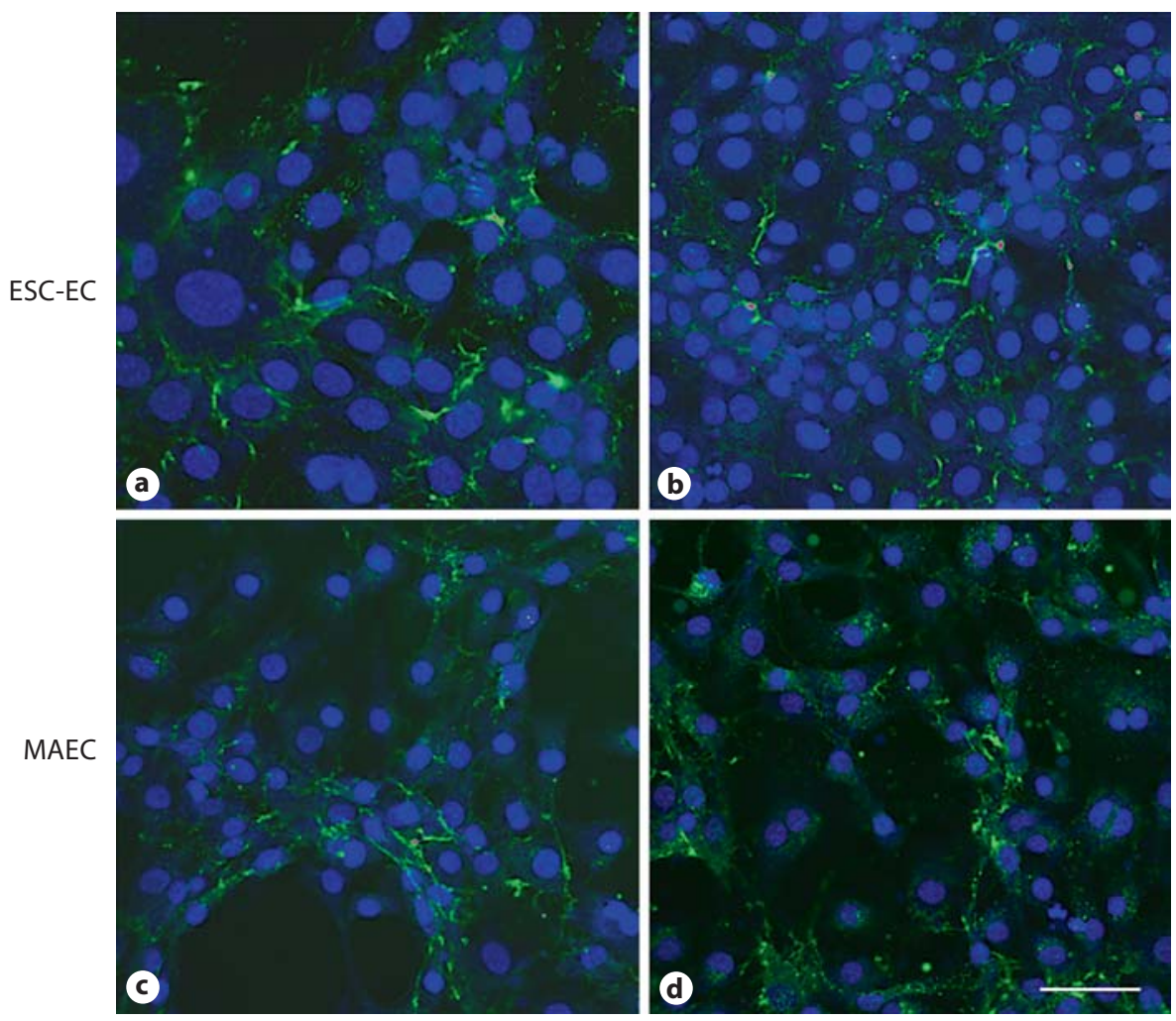

sized molecules (fig. 2). Thus, the average flux of these molecules across the MAEC and ESC-EC monolayers were similar, and not statistically significant $(\mathrm{p}<0.05)$.

\section{ESC-EC Exhibit Enhanced Vasculogenesis/}

Angiogenesis

ESC-EC exhibited increased vasculogenic and angiogenic behaviors compared with MAEC. When either ESC-EC or MAEC were seeded on Matrigel, they rapidly formed tube-like networks within $24 \mathrm{~h}$; however, the ESC-EC exhibited significantly more sprouting (fig. 3a), whereas MAEC did not exhibit clear evidence of sprouting after $24 \mathrm{~h}$ (fig. 3c). After 2 days on the Matrigel, the MAEC networks were replaced by individual cells that become rounder and cluster into aggregates (fig. 3d), and exhibit increased apoptosis (fig. 3h). In contrast, the ESCEC exhibited increased proliferation, migration and additional sprouting from a central cell aggregate (fig. $3 \mathrm{~b}, \mathrm{f}$ ) that formed tubes with apparent lumens (fig. 3i). Quantification of the vessel structures on days 1 and 2 (fig. 3j) confirms that the ESC-EC exhibit increased frequency of vessel sprouts with shorter average lengths. We conclude that ESC-EC demonstrate considerably more angiogenic sprouting potential compared with MAEC.

\section{ESC-EC Produce Appropriate ECM}

The ESC-EC were able to synthesize all of the ECM components that were analyzed: collagen type IV, collagen type I, laminin and fibronectin (fig. $4 \mathrm{a}-\mathrm{d}$ ). The integrated fluorescence intensity was measured and normalized per cell (fig. 4i). The synthesis of collagen IV by the ESC-EC (fig. 4b) compared with MAEC (fig. 4f), but very little collagen I was synthesized by either cell population. The laminin and fibronectin synthesis by both the MAEC and the ESC-EC were more robust, but somewhat lower in the ESC-EC (fig. 4c, d) compared with MAEC (fig. 4g, h).

\section{ESC-EC Take Up LDL}

A hallmark of EC function is the uptake of LDL both for normal metabolism and under pathologic conditions of atherogenesis. Here we see that both the ESC-EC and MAEC exhibited relatively homogeneous uptake of LDL throughout the monolayer cultures as indicated by the green fluorescence in each cell (fig. 5).

\section{ESC-EC Increase Cellular Adhesion Molecule}

Expression in Response to TNF- $\alpha$ Treatment

Expression of VCAM-1 and ICAM-1 was quantified by gentle dissociation from the monolayer followed by 


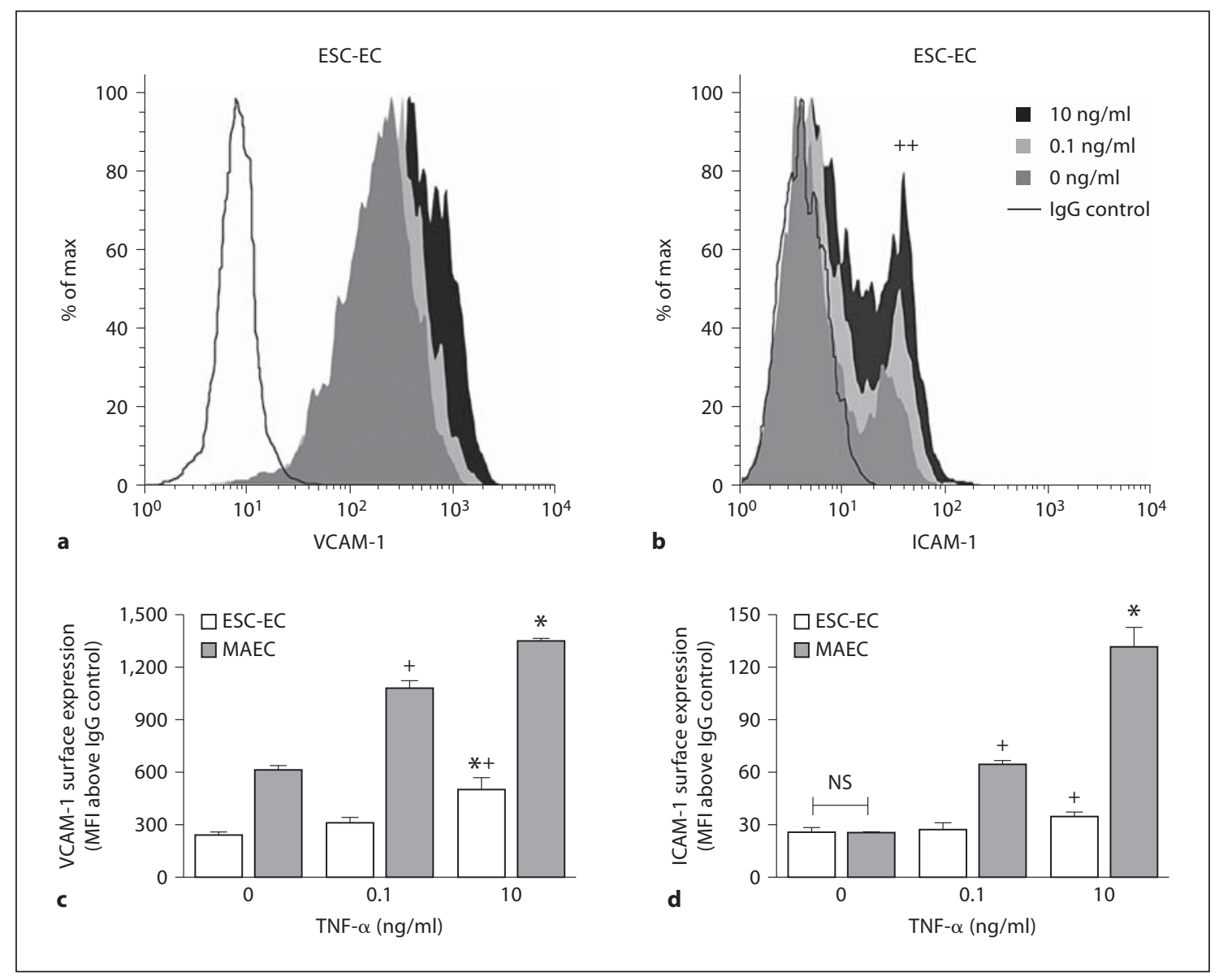

Fig. 6. ESC-EC increase ICAM-1 and VCAM-1 in response to TNF- $\alpha$. Histograms of ESC-EC surface expression of VCAM-1 (a) and ICAM-1 (b) following $4 \mathrm{~h}$ treatment with $0,0.1$, and $10 \mathrm{ng} / \mathrm{ml} \mathrm{TNF-} \alpha\left({ }^{++} \mathrm{p}<0.01\right)$ percentage of ESC-EC positive for ICAM-1 at 10 versus $0 \mathrm{ng} / \mathrm{ml}$. The VCAM-1 (c) and ICAM-1 (d) surface expression from 4 experiments was also quantified $\left({ }^{*} \mathrm{p}<0.05 \mathrm{vs} .0 .1 \mathrm{ng} / \mathrm{ml}\right.$ of same cell type; ${ }^{+} \mathrm{p}<0.05 \mathrm{vs} .0 \mathrm{ng} / \mathrm{ml}$ of same cell type). For each condition, MAEC express significantly more surface protein than ESC-EC except at $0 \mathrm{ng} / \mathrm{ml}$ for ICAM-1.

flow cytometry. VCAM-1 was significantly expressed above the IgG control at baseline in ESC-EC, but these cells revealed heterogeneity in their ICAM-1 expression with less than $15 \%$ expressing ICAM-1 at baseline (fig. 6a, b). Moreover, surface VCAM-1 increased its expression after stimulation with $0.1 \mathrm{ng} / \mathrm{ml} \mathrm{TNF}-\alpha$, and doubled its expression in response to $10 \mathrm{ng} / \mathrm{ml} \mathrm{TNF}-\alpha$ (fig. 6c). Although ESC-EC exhibited less sensitivity to TNF- $\alpha$ than MAEC, stimulation with $10 \mathrm{ng} / \mathrm{ml}$ TNF- $\alpha$ treatment significantly increased the fraction of the ESC-EC population upregulating ICAM-1 (fig. 6b, d). Following 0.1 and $10 \mathrm{ng} / \mathrm{ml}$ TNF- $\alpha$, the percentage of ICAM-1-positive ESC-EC increased to approximately 25 and $40 \%$, respectively (fig. 6b).
These data indicate that MAEC express cell surface VCAM-1 and ICAM-1 at baseline and increased surface expression in a dose-dependent manner to inflammatory stimulus. Significant increases in ICAM-1 and VCAM-1 were observed at 0.1 and $10 \mathrm{ng} / \mathrm{ml} \mathrm{TNF}-\alpha$. For each condition, MAEC expressed significantly more surface protein than ESC-EC, except at baseline, where ICAM-1 expression was equivalent for both MAEC and ESC-EC.

\section{ESC-EC Express Predominantly Venous EC Markers}

The endothelial subphenotypes (that is, venous, arterial and lymphatic) in the MAEC and ESC-EC populations were examined (fig. 7). Characterization included the ephrin B4 (EphB4) molecule that preferentially marks 


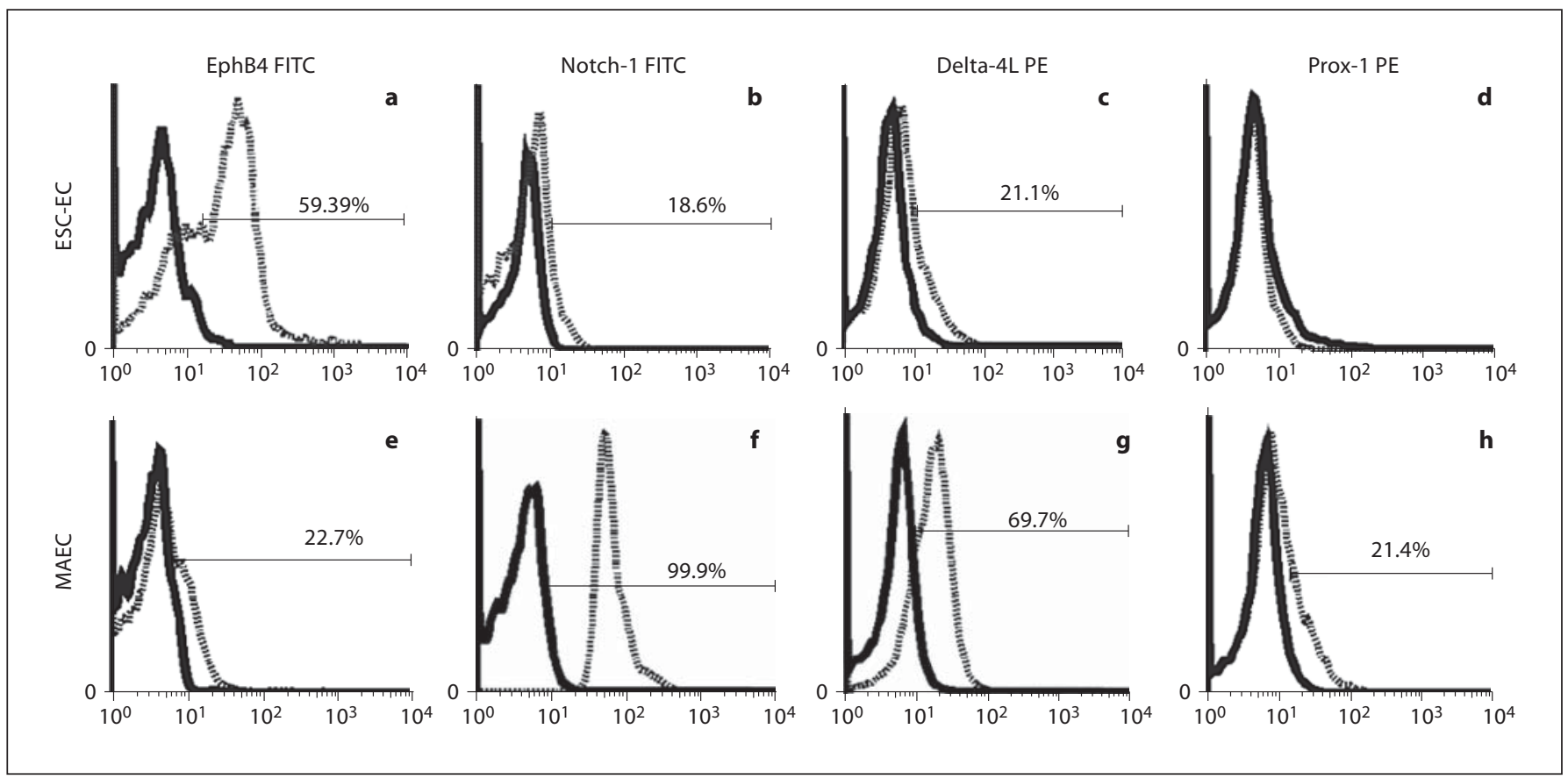

Fig. 7. ESC-EC predominantly consist of venous EC. ESC-EC and MAEC were stained with antibodies against EphB4, Notch-1, delta-4L and Prox-1, molecules specific for venous, arterial (Notch-1 and delta-4L) and lymphatic EC, respectively. Representative histograms from FACS analysis of ESC-EC (a-d) and MAEC (e-h) are shown. i EphB4 measurements $(\mathrm{n}=4)$ for venous EC, Notch-1 and delta- 1 measurements $(n=4)$ for arterial EC and Prox-1 measurements $(\mathrm{n}=2)$ for lymphatic EC were combined and plotted on a bar graph. The data indicate that both the MAEC and ESC-EC cultures contain both arterial and venous EC, but the MAEC are predominantly arterial EC (60\%), whereas the ESC-EC are predominantly venous EC (50\%). However, the differences between ESC-EC and MAEC were not statistically significant.

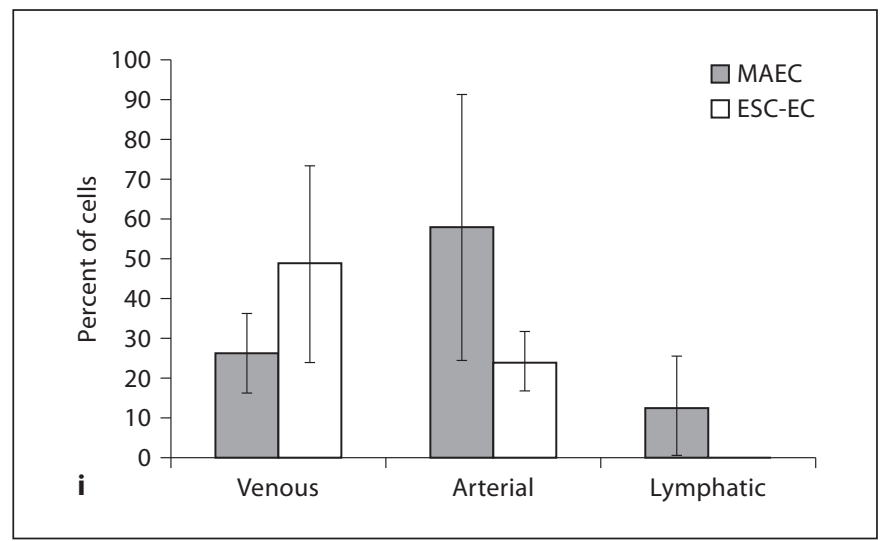

venous blood vessels [42] and belongs to a subclass of receptor tyrosine kinase proteins and regulates morphology of the cardiovascular system [43]. Arterial markers Notch-1, delta-4L and the lymphatic marker, Prox-1 [38], were also examined. One half of the population of ESC$\mathrm{EC}$ were found to express the EphB4 marker for venous EC, whereas only $20 \%$ of the cells expressed the arterial EC markers. Surprisingly, EC marker expression on MAEC also revealed heterogeneous subphenotypes as well, containing lower than the expected frequency of arterial cells, only $60 \%$, and the remainder consisting of venous (25\%) and lymphatic (10\%) EC. These data suggest that a portion of the population of MAEC dedifferentiate during passage in culture.

\section{Discussion and Conclusions}

ESC-EC are a potential inexhaustible source of functional vascular cells that exhibit the key features of a mature EC for clinical diagnostics and regenerative medicine. In this study, we examined a number of physiological responses of ESC-EC to reveal their functionality and compared these responses with MAEC. The ESC-EC constitutively synthesized and released NO into the culture medium and the amount of NO was upregulated in response to physiological shear stress. Moreover, the ESC-EC responded predictably by downregulating NO in response to the addition of TNF- $\alpha$ pro-inflammatory signal. Interestingly, when measuring the NO produced 
by a confluent layer of EC covering the $100-\mathrm{mm}^{2}$ culture dish, the NO production of the ESC-EC was comparable to that of the MAEC per area of tissue. However, once the amount of NO produced was normalized per cell, the larger MAEC did produce significantly more NO per cell than the smaller and more densely packed ESC-EC. It is interesting to note that although MAEC produced more NO than ESC-EC, the ESC-EC are also capable of producing physiologically appropriate levels of NO per area for homeostatic tissue function.

In our assay, both ESC-EC and MAEC generated an endothelial monolayer that was relatively impermeable, $<1 \%$ flux, to large molecules (70 kDa), but semi-permeable, approximately $60 \%$ flux, to small molecules (370 Da). These values are typical of normal endothelium that is resistant to the flux of large molecules, as solute permeability to dextran-70-FITC is typically less than $5 \%$ of input [44]. A transient increase in endothelial permeability to molecules on the order of 3-kDa molecules is also possible; however, these increases in permeability are typically observed in response to acute tissue injury, whereas abnormal endothelial permeability is more persistent and has been implicated in atherosclerosis, diabetic retinopathy and tumor growth [16].

Of additional interest is the increased angiogenic, and potentially tumerogenic, nature of ESC-EC when seeded on Matrigel compared to MAEC. Typically, EC create intricate spiderweb-like networks on Matrigel-coated surfaces. As expected, the MAEC formed EC cord-like structures on Matrigel. The ESC-EC also formed these same structures with increased sprouting $24 \mathrm{~h}$ after seeding, and continued to proliferate and develop into a cell mass with further sprouting from the center of the cell mass. This could potentially be explained by the use of Matrigel scaffolding material, as these results are not observed for EC seeded in three-dimensional collagen gels [2]. Matrigel is derived from Engelbreth-Holm-Swarm mouse sarcoma cells [45]. The chief components of Matrigel are structural proteins such as laminin and collagen; however, Matrigel is also highly enriched with growth factors that promote differentiation and proliferation of many cell types. The unusual behavior for our ESC-EC is not typical for mature $\mathrm{EC}$, and might be indicative of the immature or embryonic-like state of our ESC-EC, especially when combined with matrix and growth factors derived from tumors. Further studies in which shear stress or inflammatory stimuli are applied to condition the ESC-EC may facilitate their ability to progress towards a more mature EC phenotype.
Endothelial synthesis of ECM is also a critical function for the generation of a basement membrane and niche for EC survival and function. Both ESC-EC and MAEC produced collagen type IV, fibronectin and laminin on tissue culture plastic. ESC-EC also produced a low level of collagen type I. Both laminin and collagen type IV are major components of the basement membrane around blood vessels [28], and fibronectin is a key component of vasculogenesis [46]. The synthesis of these components indicates that the ESC-EC are able to synthesize components for the generation of an appropriate niche.

Vascular inflammation is important for wound repair, clearance of bacterial and viral infections, and revascularization during ischemia. Impairment of these processes results in infection, limb loss or organ failure. Thus, it is important that endothelium derived from embryonic sources for expansion and transplant function remain appropriately responsive to the pro-inflammatory milieu in which they are introduced. At baseline the confluent monolayers of ESC-EC constitutively expressed VCAM-1 and a subpopulation expressed ICAM-1 protein. These IgG superfamily members are important for endothelial progenitor cell recruitment to ischemic tissue by providing receptor targets for their $\beta_{1}$-integrin (that is, VLA-4) and $\beta_{2}$-integrin (that is, LFA-1) as demonstrated in recovery of hind limb blood flow in mouse models [34, 47]. Thus, our ESC-EC may be expected to participate in such processes in the absence of additional stimuli; however, further adhesion studies in shear are warranted in order to establish their capacity to recruit monocytes and progenitor cells. The ESC-EC demonstrated the ability to increase VCAM-1 and ICAM-1 in response to TNF- $\alpha$, but were more resistant to inflammation than MAEC. TNF$\alpha$ increased ICAM-1 on a subset of ESC-EC constitutively expressing ICAM-1, and was also able to induce nonexpressing cells to upregulate the ICAM-1 protein in a dose-dependent manner. This suggests that inflammatory stimuli may induce the differentiation of ESC-EC into mature endothelium that would be more responsive to inflammatory and other signals.

We further explored the characterization of the EC subphenotypes. Arterial specification was characterized by Notch-1 and delta- $4 \mathrm{~L}$ while venous specification was demonstrated by the expression of the EphB4 surface protein. Our data indicate the ESC-EC are composed of significantly more venous subphenotype than MAEC. Since a venous specification appears to be the default EC subphenotype during development, it is not surprising that our ESC-EC are also predominantly venous [39]. Interestingly, the MAEC did not indicate homogeneous ar- 
terial cell phenotype cultures even though the cells were isolated from the abdominal aorta. It seems that some of the MAEC have lost their arterial specification in culture, possibly due to the lack of shear stress signaling in the static culture dishes.

Unfortunately, it is difficult to compare ESC-EC with EPC isolated from blood because EPC lack a unifying phenotype. The most recent literature discusses many different types of EPC generated using different culture methods [48]. The three categories of EPC include: (1) colony-forming unit-Hill cells, (2) circulating angiogenic cells, and (3) endothelial colony-forming cells (ECFC). These cells are described by the distinct derivation methods used to generate the EPC. The colony-forming unitHill method plates peripheral blood mononuclear cells on fibronectin for 5 days and then replates the nonadherent peripheral blood mononuclear cells that subsequently grow into clusters of cells with sprouts at the peripheries. The circulating angiogenic cells are isolated from culturing the adherent cells with the nonadherent cells, and the ECFC are the expanded late colony outgrowths after the nonadherent cells are removed from cultures. Of these 3 types of EPC, all populations express VEGFR-2, CD34, vWF, eNOS and VE-cadherin; however, only ECFC late colony outgrowths form new blood vessel in vivo. Most early outgrowth cell cultures seem to be derivatives of hematopoietic progenitors expressing CD45, CD14 or $\mathrm{CD} 115$, which retain the phagocytic ability to ingest bac- teria [48]. We suspect that our ESC-EC might be most closely related to the ECFC type of EPC due to their ability to form vascular networks with lumens in vitro and expression of VEGFR-2, CD34, eNOS, VE-cadherin and respond to TNF- $\alpha$, but direct comparisons between phenotypes would be more informative $[2,4]$.

In the effort to culture ESC-EC for cell transplantation or as substrates for pharmacological testing, it is important that these stem cell-derived EC function in predictable ways following incorporation into ECM or in the inflammatory milieu in which they will be placed. Our data indicate that the ESC-EC exhibit most aspects of functional endothelium, but interesting differences remain, such as a more robust proliferative profile and a less inflammatory phenotype of the ESC-EC as compared to mature aortic EC. In addition, our ESC-EC are more consistent with a venous EC subphenotype, and we suspect that physiological shear and inflammatory stimuli may play a role in the induction of these ESC-EC to behave more like mature arterial EC.

\section{Acknowledgements}

Special thanks to Dr. Henry Forman (University of California, Merced) and Dr. David Ojcius (University of California, Merced) for access to their spectrophotometers and fluorescence microscopes. Funding for Scott Simon's laboratory was generously provided by NIH grant HL082689.

\section{References}

1 Li Z, Han Z, Wu JC: Transplantation of human embryonic stem cell-derived endothelial cells for vascular diseases. J Cell Biochem 2009;106:194-199.

$\checkmark 2$ McCloskey KE, Gilroy ME, Nerem RM: Use of embryonic stem cell-derived endothelial cells as a cell source to generate vessel structures in vitro. Tissue Eng 2005; 11:497-505.

-3 McCloskey KE, et al: Purified and proliferating endothelial cells derived and expanded in vitro from embryonic stem cells. Endothelium 2003;10:329-336.

4 McCloskey KE, et al: Embryonic stem cellderived endothelial cells may lack complete functional maturation in vitro. J Vasc Res 2006;43:411-421.

5 McCloskey KE, Stice SL, Nerem RM: In vitro derivation and expansion of endothelial cells from embryonic stem cells. Methods $\mathrm{Mol}$ Biol 2006;330:287-301.

6 Cines DB, et al: Endothelial cells in physiology and in the pathophysiology of vascular disorders. Blood 1998;91:3527-3561.
7 Ballermann BJ, et al: Shear stress and the endothelium. Kidney Int Suppl 1998;67:S100S108.

8 Boo YC, et al: Shear stress stimulates phosphorylation of endothelial nitric-oxide synthase at Ser1179 by Akt-independent mechanisms: role of protein kinase A. J Biol Chem 2002;277:3388-3396.

$\checkmark 9$ Malek AM, Izumo S, Alper SL: Modulation by pathophysiological stimuli of the shear stress-induced up-regulation of endothelial nitric oxide synthase expression in endothelial cells. Neurosurgery 1999;45:334-344, discussion 344-345.

10 Noris M, et al: Nitric oxide synthesis by cultured endothelial cells is modulated by flow conditions. Circ Res 1995;76:536-543.

$>11$ Davis ME, et al: Shear stress regulates endothelial nitric oxide synthase expression through c-Src by divergent signaling pathways. Circ Res 2001;89:1073-1080.
12 Yoshizumi M, et al: Tumor necrosis factor downregulates an endothelial nitric oxide synthase mRNA by shortening its half-life. Circ Res 1993;73:205-209.

13 mAlbelda SM, et al: Permeability characteristics of cultured endothelial cell monolayers. J Appl Physiol 1988;64:308-322.

14 Hayashi K, et al: Effects of hypoxia on endothelial/pericytic co-culture model of the blood-brain barrier. Regul Pept 2004;123: 77-83.

$>15$ Sharkawy AA, et al: Engineering the tissue which encapsulates subcutaneous implants. I. Diffusion properties. J Biomed Mater Res 1997;37:401-412.

16 Carmeliet P: Angiogenesis in health and disease. Nat Med 2003;9:653-660.

17 Risau W: Mechanisms of angiogenesis. Nature 1997;386:671-674.

$\checkmark 18$ Asahara T, et al: Isolation of putative progenitor endothelial cells for angiogenesis. Science 1997;275:964-967. 
19 Asahara T, et al: Bone marrow origin of endothelial progenitor cells responsible for postnatal vasculogenesis in physiological and pathological neovascularization. Circ Res 1999;85:221-228.

20 Ribatti D, et al: Postnatal vasculogenesis. Mech Dev 2001;100:157-163.

-21 Davis GE, Camarillo CW: Regulation of endothelial cell morphogenesis by integrins, mechanical forces, and matrix guidance pathways. Exp Cell Res 1995;216:113-123.

-22 Deroanne CF, Lapiere CM, Nusgens BV: In vitro tubulogenesis of endothelial cells by relaxation of the coupling extracellular matrix-cytoskeleton. Cardiovasc Res 2001;49: 647-658.

23 Vernon RB, et al: Reorganization of basement membrane matrices by cellular traction promotes the formation of cellular networks in vitro. Lab Invest 1992;66:536-547.

-24 Conway EM, Collen D, Carmeliet P: Molecular mechanisms of blood vessel growth. Cardiovasc Res 2001;49:507-521.

-25 Davis GE, Senger DR: Endothelial extracellular matrix: biosynthesis, remodeling, and functions during vascular morphogenesis and neovessel stabilization. Circ Res 2005; 97:1093-1107.

-26 Hudson BG, Reeders ST, Tryggvason K: Type IV collagen: structure, gene organization, and role in human diseases. Molecular basis of Goodpasture and Alport syndromes and diffuse leiomyomatosis. J Biol Chem 1993; 268:26033-26036.

27 Rhodes JM, Simons M: The extracellular matrix and blood vessel formation: not just a scaffold. J Cell Mol Med 2007;11:176-205.

-28 Beck K, Hunter I, Engel J: Structure and function of laminin: anatomy of a multidomain glycoprotein. FASEB J 1990;4:148160 .
29 Gospodarowicz D, et al: The production and localization of laminin in cultured vascular and corneal endothelial cells. J Cell Physiol 1981;107:171-183.

30 Astrof S, Hynes RO: Fibronectins in vascular morphogenesis. Angiogenesis 2009;12:165175.

31 Zhou X, et al: Fibronectin fibrillogenesis reg ulates three-dimensional neovessel formation. Genes Dev 2008;22:1231-1243.

32 Libby P: Inflammation in atherosclerosis. Nature 2002;420:868-874.

33 O’Brien KD, et al: Neovascular expression of E-selectin, intercellular adhesion molecule-1, and vascular cell adhesion molecule-1 in human atherosclerosis and their relation to intimal leukocyte content. Circulation 1996;93:672-682.

34 Duan H, et al: LFA-1 and VLA-4 involved in human high proliferative potential-endothelial progenitor cells homing to ischemic tissue. Thromb Haemost 2006;96:807-815.

-35 Werner N, Nickenig G: Influence of cardiovascular risk factors on endothelial progenitor cells: limitations for therapy? Arterioscler Thromb Vasc Biol 2006;26:257-266.

36 Chatzizisis YS, et al: Role of endothelial shear stress in the natural history of coronary atherosclerosis and vascular remodeling: molecular, cellular, and vascular behavior. J Am Coll Cardiol 2007;49:2379-2393.

37 Aranguren XL, et al: In vitro and in vivo arterial differentiation of human multipotent adult progenitor cells. Blood 2007;109:26342642 .
38 Yamashita JK: Differentiation of arterial, venous, and lymphatic endothelial cells from vascular progenitors. Trends Cardiovasc Med 2007;17:59-63.

39 Red-Horse K, et al: Coronary arteries form by developmental reprogramming of venous cells. Nature 2010;464:549-553.

40 Dewey CF Jr, et al: The dynamic response of vascular endothelial cells to fluid shear stress. J Biomech Eng 1981;103:177-185.

41 Jo H, Song H, Mowbray A: Role of NADPH oxidases in disturbed flow- and BMP4-induced inflammation and atherosclerosis. Antioxid Redox Signal 2006;8:1609-1619.

42 Gale NW, et al: Ephrin-B2 selectively marks arterial vessels and neovascularization sites in the adult, with expression in both endothelial and smooth-muscle cells. Dev Biol 2001;230:151-160.

43 Swift MR, Weinstein BM: Arterial-venous specification during development. Circ Res 2009; 104:576-588.

44 Yosef N, Xia RH, Ubogu EE: Development and characterization of a novel human in vitro blood-nerve barrier model using primary endoneurial endothelial cells. J Neuropathol Exp Neurol 2010;69:82-97.

45 Kleinman HK, Martin GR: Matrigel: basement membrane matrix with biological activity. Semin Cancer Biol 2005;15:378-386.

-46 Astrof S, Hynes RO: Fibronectins in vascular morphogenesis. Angiogenesis 2009;12:165175.

47 Chavakis E, et al: Role of $\beta 2$-integrins for homing and neovascularization capacity of endothelial progenitor cells. J Exp Med 2005; 201:63-72.

48 Hirschi KK, Ingram DA, Yoder MC: Assessing identity, phenotype, and fate of endothelial progenitor cells. Arterioscler Thromb Vasc Biol 2008;28:1584-1595. 